\title{
Utilization of Industrial Rosa damascena Mill. By-products and Cocoa Pod Husks as Natural Preservatives in Muffins
}

\author{
Rosen Chochkov ${ }^{1}$, Rositsa Denkova², Zapryana Denkova³, Petko Denev4, Ivelina Vasileva5, \\ Tzvetelin Dessev ${ }^{1}$, Apostol Simitchiev ${ }^{6}$, Ventsislav Nenov ${ }^{6}$, Anton Slavov ${ }^{5 *}$
}

\footnotetext{
1 Department Technology of Cereals, Fodder, Bread and Confectionary Products, Technological Faculty, University of Food Technologies, 26 Maritsa Blvd., 4002 Plovdiv, Bulgaria

2 Department of Biochemistry and Molecular Biology, Technological Faculty, University of Food Technologies, 26 Maritsa Blvd., 4002 Plovdiv, Bulgaria

${ }^{3}$ Department of Microbiology, Technological Faculty, University of Food Technologies, 26 Maritsa Blvd., 4002 Plovdiv, Bulgaria

${ }^{4}$ Laboratory of Bioactive Substances, Institute of Organic Chemistry with Centre of Phytochemistry, Bulgarian Academy of Sciences, 139 Ruski Blvd., 4000 Plovdiv, Bulgaria

${ }^{5}$ Department of Organic Chemistry and Inorganic Chemistry, Technological Faculty, University of Food Technologies, 26 Maritsa Blvd., 4002 Plovdiv, Bulgaria

${ }^{6}$ Department of Machines and Apparatuses for Food \& Biotechnological Industry, Technical Faculty, University of Food Technologies, 26 Maritsa Blvd., 4002 Plovdiv, Bulgaria

*Corresponding author, e-mail: antons@uni-plovdiv.net
}

Received: 01 March 2021, Accepted: 02 June 2021, Published online: 09 November 2021

\begin{abstract}
Cocoa Pod Husks (CPH) and by-product from supercritical $\mathrm{CO}_{2}$ extracted Rosa damascena Mill. (RDCO2) were used as biopreservatives in muffins. Both by-products were rich source of polyphenols: $28.3 \pm 0.6 \mathrm{mg} / \mathrm{g}$ Dry Weight (DW) and $17.9 \pm 0.7 \mathrm{mg} / \mathrm{g}$ DW RDCO2 and $\mathrm{CPH}$, respectively, and exhibited potent antioxidant capacity: $449.1 \pm 8.5 \mu \mathrm{mol}$ Trolox Equivalents (TE)/g DW (by ORAC method) and $58.9 \pm 2.1 \mu \mathrm{mol}$ Gallic Acid Equivalents (GAE)/g DW (by HORAC method) for the RDCO2, and $373.8 \pm 9.0 \mu \mathrm{mol}$ TE/g DW (by ORAC) and $36.8 \pm 3.8 \mu \mathrm{mol}$ GAE/g DW (by HORAC) for the CPH. RDCO2 extracts successfully inhibited development of several important pathogenic and saprophytic microorganisms causing microbial spoilage of food systems. The control muffins were good for consumption up to the $17^{\text {th }}$ day, while the products supplemented with RDCO2 and $\mathrm{CPH}$ : until $20^{\text {th }}$ day of storage at $22 \pm 0.5^{\circ} \mathrm{C}$. The amount of dietary fibers in muffins supplemented with both by-products increased 3 times $(8.57 \pm 0.12 \%)$ compared to control $(2.91 \pm 0.12 \%)$ and the polyphenolic compounds increased 2.5 times (from $50.0 \pm 0.3$ for the control to $185.9 \pm 0.6 \mathrm{mg} / \mathrm{g} \mathrm{DW}$ ). For the first time by-product of supercritical $\mathrm{CO}_{2}$ extraction of Rosa damascena Mill. was characterized and used as natural and cheap biopreservative.
\end{abstract}

\section{Keywords}

muffin, biopreservative, Rosa damascena Mill., Cocoa Pod Husks (CPH), by-product valorization

\section{Introduction}

Bakery products are characterized with a relatively short shelf life. Their exteriority, safety and quality depend on the baking-consumption period, storage conditions and preservatives added. The main reasons for deterioration and loss of quality are changes in the water content / water activity, temperature and microorganisms' development. Different approaches for extending shelf life of bakery products were employed, such as: packaging, often in modified atmosphere, addition of lactic acid bacteria, utilization of various fungal inhibitors (ethanol, propionic, sorbic, benzoic, acetic acid, etc.), addition of antimicrobial agents (chitosan, essential oils, legume hydrolysates etc.), addition of antistaling agents, etc. [1-4]. Utilization of agro-industrial by-products is a rare practice, although these residues are rich in biologically active substances with potent antibacterial activity [5].

Muffins - the sweet spongy bakery products are widely consumed. The popularity of muffins, the modern health trends and consumers' demands, has led to emergence of various recipes. The major goals were improved functional and health properties: by replacing the sucrose $[6,7]$ or the fat with fibers [8], decreasing or removing the gluten 
by different pretreatments or wheat flour replacement [9], lowering the calorie value, and stalling retardation [1]. Moreover, substitution of flour with various high-fiber preparations, rich in biologically active substances, was widely utilized for enrichment, functionalization and shelf life extension of the bakery products $[10,11]$.

The rose oil manufacturing is a source of huge amounts of solid and liquid by-products which remained unutilized although studies suggested they could be successfully valorized [12]. The essential oil raw materials are mainly processed by hydrodistillation. Recently extraction with liquefied gases, such as $\mathrm{CO}_{2}$, freons (1,1,1-trifluoroethane R143a), became an alternative and had advantage to produce mainly solid residues. To the best of our knowledge there are no data on the characterization and utilization of Rosa damascena Mill. by-product (RDCO2), obtained after $\mathrm{CO}_{2}$ extraction.

Cocoa industry generates large amount of by-products: Cocoa Pod Husks (CPH), shells, cocoa pulp juice, etc. The increasing demand for cocoa and search for ingredients rich in bioactive compounds gave ground to investigate the possibility of replacing cocoa by carob powder in the bakery products. The $\mathrm{CPH}$ are the main residues and they were utilized as animal feed, cocoa gum and source of antioxidants [13]. Both, $\mathrm{CPH}$ and RDCO2 were found to be rich source of biologically active substances [14] and they could be utilized as biopreservatives in food systems.

Isolation and reuse of valuable functional ingredients and nutraceuticals from undervalued and underutilized bio-resources from agricultural and food industry became one of the important milestones of the "green" and circular economy. The recovery of such high-value substances was proposed to follow the so-called 5-stage universal recovery processing $[15,16]$ and emerging non-conventional extraction technologies, which can avoid utilization of higher temperatures and potentially toxic extractants, were applied as alternative [17, 18]. Physical and physicochemical pretreatments, such as high voltage electrical discharge, pulsed electric field, ultrasound assisted extraction, etc., were successfully applied for significant increase of the recovery of the targeted bioactive compounds from residual biomasses [16]. Separation of the bioactive substances: proteins, dietary fibers, polyphenols, alkaloids, anthocyanins, tannins, flavonoids, sugars, being recovered from agricultural and food industry wastewaters is also a challenging task and various techniques, such as ultrafiltration, nanofiltration, chromatographic methods, etc., were investigated and applied in practice [15].
Nevertheless, in certain cases direct application and addition (without isolation and purification of bio-active compounds) of by-products could be an alternative [5, 14].

Replacement, partial or full, of some of the ingredients of the bakery products usually alters appearance, taste and physico-chemical properties of batter, hence the final product [8]. A large assortment of functional ingredients, preparations or by-products is now available and has been investigated. Besides, addition of some of the preparations and by-products into the bakery products improve their antimicrobial stability, shelf life and health promotional properties, serving as natural preservatives [5]. Nowadays, food safety and security became of high priority and concern and for this reason various approaches, methodologies and sustainable decisions were recently introduced. Besides, the constantly emerging challenging threats demands more investigations and response of the food scientists and industry in order to provide sustainable solutions for application of bioactive ingredients of foods and herbs for the support of immune system against infections. Moreover, the possibilities of infections spreading through and by the food chain deserve special attention $[19,20]$. Hence, the present study aimed to investigate partial replacement of wheat flour with $\mathrm{CPH}$ and $\mathrm{RDCO} 2$ for muffins preparation and shelf life, quality and aroma profile of the product.

\section{Materials and methods}

\subsection{Materials}

The $\mathrm{RDCO} 2$ was obtained after industrial $\mathrm{CO}_{2}$ extraction of rose flowers (EKOMAAT, Mirkovo, Bulgaria; 2017). The CPH were provided by ANES-96 Ltd. (Plovdiv, Bulgaria). Both by-products were milled and sieved (particle size $0.5-0.6 \mathrm{~mm}$ ) prior to analyses and work.

\subsection{Methods}

\subsubsection{Preparative methods}

Muffins preparation: Based on the basic muffins recipes, batters visco-elastic behavior and sensory properties of the preparatory tests, two control samples (without $(\mathrm{Cl})$ and with (C2) commercial cocoa powder) and three variants (with added RDCO2 flour (V1), with replacement only of the commercial cocoa powder with CPH flour (V2) and with addition of both $\mathrm{CPH}$ and RDCO2 flour (V3)) were chosen (Table 1).

The wheat flour (type 550), baking soda, sugar, eggs, sunflower oil, yogurt, and low-fat cocoa were obtained from the local market. The muffins were prepared as 
Table 1 Type and amounts of ingredients used for muffins preparation

\begin{tabular}{|c|c|c|c|c|c|}
\hline \multirow{2}{*}{ Ingredient } & \multicolumn{5}{|c|}{ Variant, $g$} \\
\hline & $\mathrm{C} 1$ & $\mathrm{C} 2$ & V1 & $\mathrm{V} 2$ & V3 \\
\hline Wheat flour & 29.2 & 28.3 & 27.6 & 28.3 & 26.7 \\
\hline Eggs & 8.9 & 8.9 & 8.9 & 8.9 & 8.9 \\
\hline Sugar & 24.4 & 24.4 & 24.4 & 24.4 & 24.4 \\
\hline Sunflower oil & 14.9 & 14.9 & 14.9 & 14.9 & 14.9 \\
\hline Yogurt (2 \% fat) & 22.3 & 22.3 & 22.3 & 22.3 & 22.3 \\
\hline Baking soda $\left(\mathrm{NaHCO}_{3}\right)$ & 0.3 & 0.3 & 0.3 & 0.3 & 0.3 \\
\hline Low-fat natural cocoa & - & 0.9 & - & - & - \\
\hline $\mathrm{CPH}$ flour & - & - & - & 0.9 & 0.9 \\
\hline RDCO2 flour & - & - & 1.6 & - & 1.6 \\
\hline
\end{tabular}

follow: the eggs and the sugar were mixed $(5 \mathrm{~min})$; the sunflower oil was added; the yogurt and baking soda were carefully mixed and added to the previous mixture; the wheat flour (and the RDCO2 flour, and CPH flour, if present) were sieved, mixed and added to the liquid components; the dough was homogenized (15 min) and $50 \mathrm{~g}$ portions were dozed in molds; the muffins were baked (25 min) using an electric oven (SALVA E-25, Salva, Spain) at $180^{\circ} \mathrm{C}$. When ready the muffins were left to cool down for $1 \mathrm{~h}$ at $22 \pm 0.5^{\circ} \mathrm{C}$.

\subsubsection{Analytical methods}

By-products characterization

The protein amount was assessed by the Kjeldahl method (UDK152, Velp-Scientifica, Italy) multiplying the nitrogen quantity by 6.25 . Inorganic matters were determined after ashing $5 \mathrm{~g}$ sample at $605{ }^{\circ} \mathrm{C}$. The dietary fibers content was evaluated according to AOAC 991.43 with Bioquant 1.12979.0001 enzyme kit (Merck, Germany). GC-MS analyses on Agilent GC7890 with mas-selective detector Agilent MD5975 and HP-5ms column after extraction of the by-products with 20 volumes $70 \%$ ethanol using ultrasonication (VWR, Malaysia; $45 \mathrm{kHz}, 30 \mathrm{~W} ; 45^{\circ} \mathrm{C}$; $15 \mathrm{~min}$ ), were employed for determination of polar aroma and non-volatile compounds according to [21].

\section{Total polyphenols and antioxidant capacity}

The amount of polyphenols was assessed as described [22] using gallic acid (Sigma-Aldrich, Germany) as standard. The antioxidant capacity was evaluated by ORAC (Oxygen Radical Absorbance Capacity) and HORAC (Hydroxyl Radical Averting Capacity) methods [12] and the results were expressed as $\mu \mathrm{M}$ Trolox Equivalents (TE)/g and $\mu \mathrm{mol} \mathrm{GAE} / \mathrm{g}$, respectively.

\section{Batter and baked muffins characterization}

The visco-elastic behavior of muffins' batter was studied using rotary viscometer Brookfield RVDV-II+Pro
(Middleboro, USA), comprising a metal cylinder with a water jacket SC4-13R and a cylindrical spindle with conical head SC4-27. The measuring cylinder was filled with $10.4 \mathrm{ml}$ batter. Preliminary experiments were performed in order to specify the range of shear rates. The apparent viscosity and shear stress were measured at various shear rates. All curves were fitted to the Herschel-Bulkley model, according to Eq. (1):

$\tau=\tau_{0}+k \times D^{n}$

where $\tau$ : the shear stress, $\mathrm{Pa} ; \tau_{0}$ : the yield stress, $\mathrm{Pa} ; k$ : the consistency index, $\mathrm{Pa} \cdot \mathrm{s}^{\mathrm{n}} ; n$ : the flow index.

The physico-chemical parameters: height, diameter, volume and moisture of the muffins, and the gas pore distribution pattern were evaluated as described [5].

Antimicrobial activity of extracts and muffins shelf-life

The antimicrobial activity of $\mathrm{CPH}$ and RDCO2 extracts was evaluated according to [5]. The microorganisms employed were as follow: Escherichia coli ATCC 25922, Proteus vulgaris ATCC 6380, Pseudomonas aeruginosa NBIMCC 1370, Staphylococcus aureus ATCC 25923, Enterococcus faecalis ATCC 19433, Listeria monocytogenes ATCC 19111, Salmonella abony NTCC 6017, Candida albicans NBIMCC 74, Candida utilis ATCC 42402, Aspergillus niger ATCC 1015, Penicillium chrysogenum ATCC 28089, Bacillus subtilis ATCC 19659, Fusarium moniliforme ATCC 38932 and Rhizopus arrhizus ATCC 11145. All microorganisms used in the present study are included in the microorganisms' collection of Microbiology department, University of Food Technologies-Bulgaria. Briefly, the microorganisms were cultured on LBG-agar (comprising of tryptone $(10 \mathrm{~g} / \mathrm{L})$, yeast extract $(5 \mathrm{~g} / \mathrm{L}), \mathrm{NaCl}$ $(10 \mathrm{~g} / \mathrm{L})$, glucose $(10 \mathrm{~g} / \mathrm{L})$ and agar $(15 \mathrm{~g} / \mathrm{L})$ with $\mathrm{pH} 7.5$ (Laboratorios Conda S.A., Madrid, Spain) at $37 \pm 1{ }^{\circ} \mathrm{C}$ for $36 \mathrm{~h}$. The cultured microorganisms were suspended in sterile saline solution ( $5 \mathrm{~g} / \mathrm{L} \mathrm{NaCl}$, Merck, Germany) for obtaining microorganisms suspensions.

The disc-diffusion test (performed in quadruplicate) was employed for studying antimicrobial activity. The melted LBG-agar was put in Petri dishes, left to harden and the prepared medium was spread plated with the investigated microorganisms. Decimal dilutions (at $1 \times, 10 \times$ and $100 \times$ ) of the RDCO2 and $\mathrm{CPH}$ extracts in saline solution were used for determination of Minimum Inhibitory Concentration (MIC). The respective diluted extract $(6 \mu \mathrm{L})$ was transferred on paper discs with diameter $6 \mathrm{~mm}$. The diameters of the clear zones around the paper discs (in millimeters) after 48 hours of incubation of the dishes (at $30^{\circ} \mathrm{C}$ for saprophytes and at $37{ }^{\circ} \mathrm{C}$ 
for pathogens) were determined. The lowest extract concentration which was able to inhibit the growth was indicated as MIC.

Immediately after cooling down the muffins ( $\sim 1$ hour) were examined for Coliforms (ISO4831, ISO4832), Escherichia coli (ISO16649-1-3), Salmonella sp. (ISO6579), coagulase-positive Staphylococci (ISO68881-3), Bacillus cereus (ISO7932) and microscopic fungi spores (ISO7954). Then the muffins were packed separately in commercial polypropylene bags (150 gauge) and stored at $22 \pm 0.5{ }^{\circ} \mathrm{C}$ for 25 days in a laboratory incubator TB150 (Robotika, Velingrad, Bulgaria) at $60 \% \pm 5 \%$ relative humidity for shelf life determination. The water activity was determined at $22 \pm 0.5^{\circ} \mathrm{C}$ with $a_{w}$-meter ER-84 (Novasina, Switzerland) with a RTD-42 sensor block and the water content with Kern MLB50-3 (Kern \& Sohn, Germany). The bacterial and fungal spoilage of muffins during storage was determined as described [3].

Sensory analysis

Nineteen (21-45 years old) consumers, 10 female and 9 male, evaluated muffins acceptability (ISO 13299:2016) by scoring the appearance, crust color, crumb color, porosity, crumb softness, mastication, odor, taste, and aftertaste. The muffins acceptability range was set up from 1 to 9: 1 . negative perception or not detecting; 5. neither like nor dislike; 9. positively evaluated or strongly detecting. The muffins were coded and pieces (around $1.5 \times 1.5 \mathrm{~cm}$ ) were submitted to each tester. Between the different samples testing plain water was provided for each panelist.

\subsection{Statistical analysis}

The results were presented as average \pm SD of at least three repetitions. Statistical analysis was performed using MS Excel with installed Real Statistics Resource Pack ver 2010 (Release 7.7.1). Statistical significance was detected by one way ANOVA (Tukey's test; $p<0.05$ ).

\section{Results and discussion}

\subsection{Characterization of RDCO2 and CPH}

Recently utilization of supercritical $\mathrm{CO}_{2}$ extraction became an alternative for extraction due to the lower temperature and the easiness of extractant removal. This in fact led to lack of information for the composition of by-product generated by supercritical $\mathrm{CO}_{2}$ extraction of Rosa damascena. $\mathrm{CPH}$, one of the main residue of the chocolate industry, is readily abundant by-product known for its antioxidant and antimicrobial properties [13]. For this reason analyses were performed in order to obtain detailed data for the composition of the by-products.
Both residues were rich in polyphenols: $28.3 \pm 0.6 \mathrm{mg} / \mathrm{g}$ Dry Weight (DW) and $17.9 \pm 0.7 \mathrm{mg} / \mathrm{g}$ DW RDCO2 and $\mathrm{CPH}$, respectively. Since the polyphenols were among the main substances responsible for the antioxidant activity $[5,12]$, this reflected on the antioxidant capacity of the by-products: $449.1 \pm 8.5 \mu \mathrm{mol}$ TE/g DW (ORAC) and $58.9 \pm 2.1 \mu \mathrm{mol}$ GAE/g DW (HORAC) for the RDCO2, and $373.8 \pm 9.0 \mu \mathrm{mol} \mathrm{TE} / \mathrm{g}$ DW (ORAC) and $36.8 \pm 3.8 \mu \mathrm{mol}$ GAE/g DW (HORAC) for CPH. These results suggested that both by-products could be utilized as natural source of dietary antioxidant with potential industrial application. Additionally, the technological process for industrial treatment of rose flowers by supercritical $\mathrm{CO}_{2}$ extraction is a prerequisite the remaining biomass to be more convenient as a substrate for further valorization. Similar studies showed successful isolation and utilization of polyphenols derived from food industry by-products for food and non-food purposes [23-25]. The main source of polyphenols in these studies, focusing on the olive oil by-products valorization, was the wastewaters produced during pressing or extraction. In our case the traditional steam distillation of Rosa damascena generates solid and liquid by-products and the polyphenols could be recovered from the wastewaters by physical, thermal, physicochemical or chromatographic methods [23]. The solid by-products could be used as source of polyphenols and fibers also [5, 14]. A recent study explored the potential of pink guava by-product for combined extraction of valuable bioactive components as a complex having antioxidant capacity and containing Soluble Dietary Fibers (SDF) [26]. Furthermore, by GC-MS were determined polar aroma and non-volatile compounds in the by-products (Table S1 and Table S2).

Nowadays, the consumers demand nutritional, healthy, convenient and fresh products with minimum (or without if possible) addition of artificial preservatives. In order to satisfy these demands new emerging technologies for ensuring food quality and safety were introduced by the industry [27, 28]. Special attention in this regard (having in mind the Corona crisis, post-lockdown period and its influence on the food chains and supply) should be paid on four issues of the food sector, namely food safety, bioactive food substances and their enrichment, food security and sustainability. Additionally, bio-preservatives or naturally occurring bioactive compounds with antimicrobial activity could be used for ensuring shelflife prolongation and preparation of high-quality functional food systems [29]. In order to estimate the potential of both by-products as biopreservatives antimicrobial activity against some of the most common pathogens and 
saprophytes was assessed. Extracts from both by-products were able to inhibit development of all investigated microorganisms, the rose by-product extract demonstrating greater antimicrobial activity against pathogens, while the inhibitory activity of the two extracts against saprophytes was comparable (Table S3).

The antimicrobial activity of the RDCO2 could be explained with presence of substances such as: malic acid [30], gallic acid [31], caffeic acid [32], and phenethyl alcohol [33]. The microorganisms' suppression of $\mathrm{CPH}$ was a result of components, such as: $o$ - and $p$-hydroxybenzoic acid, malic acid [34], vanillic acid [35], protocatechuic acid [36], $p$-coumaric acid, ferulic acid [31], caffeic acid, catechin and epicatechin [32]. The inhibitory activity against pathogens and saprophytes rendered the RDCO2 and $\mathrm{CPH}$ as natural biopreservatives with potential application in food systems.

\subsection{Preparation and characterization of muffin batters}

The viscosity of batter is an important physical and structural parameter closely related to the final quality of the product [7]. Knowledge of the flow behavior is essential in process design and product quality evaluation. The data (Fig. 1 (a)) revealed that viscosity decreased as the shear rate increased which is an indication for the pseudoplastic behavior of the samples. The shear stress versus the shear rate plot for all samples (Fig. 1 (b)) suggested non-Newtonian nature of the batters as the obtained dependency is non-linear.

The yield stress is a critical value quantifying the amount of stress that the product may experience before it begins to flow. Before reaching that stress, the product behaves like a solid. The disperse system of all batters broke down at low yield stresses (Table S4).

The largest deformation occurred in sample V1 as evidenced by the low consistency index. V1 batter along with C2 had the lowest apparent viscosity (Fig. 1 (a)) and shear stress (Fig. 1 (b)). Considering that in $\mathrm{C} 1$ the apparent viscosity was higher by $34 \%$, it can be concluded that addition of the above mentioned ingredients led to a slower compression of the batter. A similar trend for decrease of the apparent viscosity with increased replacement of the wheat flour with resistant starch was observed [37]. Significant increase in the consistency index $(k)$ was found in sample $\mathrm{C} 1$ which also had the highest apparent viscosity and shear stress obtained. The $\mathrm{C} 1$ sample had higher amount of wheat flour which resulted in a faster absorption of the liquid phase. The consistency index of V2 was $15 \%$ higher than those of $\mathrm{C} 1$. This could be due to the

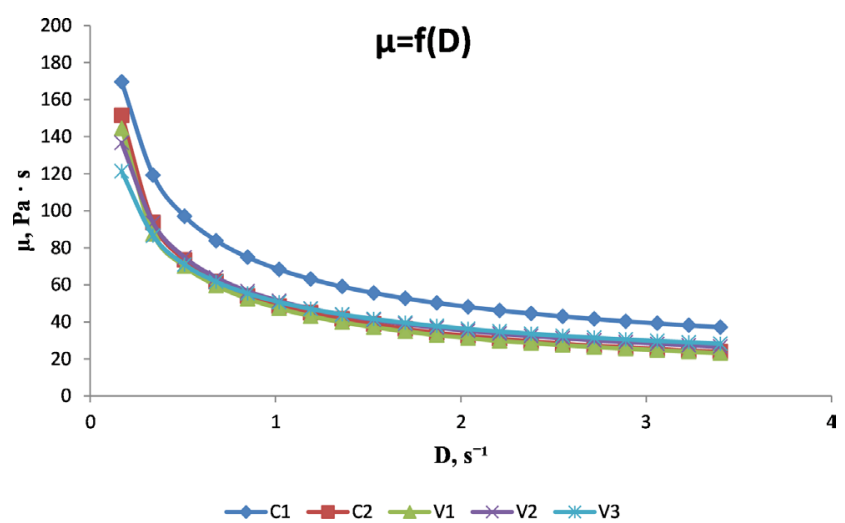

(a)

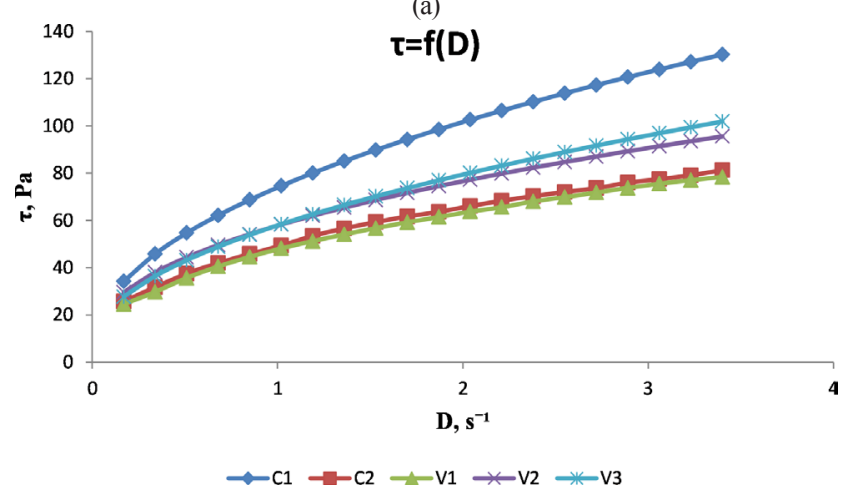

(b)

Fig. 1 Rheological properties of batters prepared with RDCO2 and $\mathrm{CPH}$. (a) Apparent viscosity $(\mu, \mathrm{Pa} \cdot \mathrm{s})$ as a function of shear rate $\left(D, \mathrm{~s}^{-1}\right)$; (b) Shear stress $(\tau, \mathrm{Pa})$ as a function of shear rate $\left(D, \mathrm{~s}^{-1}\right)$

presence of $5 \%$ powder of $\mathrm{CPH}$, which is known for its good absorption properties [38]. The V3 in which both by-products were used to partially replace wheat flour had the highest yield stress value. The flow index $n$ measures the deviation from Newtonian behavior of the product. If the product is Newtonian $n=1$, pseudoplastic when $n<1$, and dilatant when $n>1$. The pseudoplasticity of the batters was confirmed by their flow index (Table S4). The sample that was closer to Newtonian behavior was V3.

\subsection{Preparation and characterization of muffins}

The muffins were subjected to analyses and several important parameters were determined (Table 2).

The data presented in Table 2 suggested that addition of $\mathrm{CPH}$ and $\mathrm{RDCO} 2$ did not result in significant changes in the H/D ratio of the muffins but the specific volume of the final products decreased. Similar results for the volume reduction were reported for muffins with added resistant starch [37]. The total ash content increased significantly and the V3 has three times more mineral content compared to $\mathrm{C} 1$. Addition of RDCO2 augmented the Total Dietary Fiber (TDF) content in the final product two 
Table 2 Quantitative chemical and physico-chemical parameters of muffins prepared with added RDCO2 and CPH

\begin{tabular}{|c|c|c|c|c|c|}
\hline & $\mathrm{C} 1$ & $\mathrm{C} 2$ & $\mathrm{~V} 1$ & $\mathrm{~V} 2$ & V3 \\
\hline $\mathrm{H} / \mathrm{D}$ ratio & $0.78 \pm 0.09^{\mathrm{a}}$ & $0.71 \pm 0.09^{\mathrm{a}}$ & $0.71 \pm 0.07^{\mathrm{a}}$ & $0.76 \pm 0.06^{\mathrm{a}}$ & $0.81 \pm 0.06^{\mathrm{a}}$ \\
\hline Losses during baking, $\%$ & $14.3 \pm 0.7^{\mathrm{a}}$ & $13.6 \pm 4.3^{\mathrm{a}}$ & $13.8 \pm 1.7^{\mathrm{a}}$ & $15.7 \pm 1.9^{\mathrm{a}}$ & $17.3 \pm 3.4^{\mathrm{a}}$ \\
\hline Volume, $\mathrm{cm}^{3}$ & $90.0 \pm 0.5^{\mathrm{a}}$ & $78.3 \pm 4.3^{\mathrm{b}}$ & $79.3 \pm 1.2^{\mathrm{b}}$ & $83.3 \pm 2.9^{b}$ & $80.0 \pm 5.0^{\mathrm{b}}$ \\
\hline Specific volume, $\mathrm{cm}^{3} / \mathrm{g}$ & $2.10 \pm 0.02^{\mathrm{a}}$ & $1.84 \pm 0.03^{\mathrm{b}}$ & $1.84 \pm 0.01^{\mathrm{b}}$ & $1.95 \pm 0.07^{\mathrm{c}}$ & $1.90 \pm 0.15^{\mathrm{d}}$ \\
\hline Mineral content, $\%$ & $0.33 \pm 0.10^{\mathrm{a}}$ & $0.68 \pm 0.01^{\mathrm{b}}$ & $0.58 \pm 0.13^{\mathrm{b}}$ & $0.72 \pm 0.04^{b}$ & $0.91 \pm 0.03^{\mathrm{c}}$ \\
\hline Proteins, $\%$ & $8.83 \pm 0.12^{\mathrm{a}}$ & $9.41 \pm 0.11^{\mathrm{a}}$ & $9.20 \pm 0.09^{\mathrm{a}}$ & $10.69 \pm 0.12^{\mathrm{b}}$ & $9.45 \pm 0.15^{\mathrm{a}}$ \\
\hline $\mathrm{TDF}^{*}, \%$ & $2.91 \pm 0.12^{\mathrm{a}}$ & $2.99 \pm 0.13^{\mathrm{a}}$ & $6.51 \pm 0.15^{b}$ & $4.13 \pm 0.10^{c}$ & $8.57 \pm 0.12^{\mathrm{d}}$ \\
\hline SDF, $\%$ & $0.64 \pm 0.10^{\mathrm{a}}$ & $0.65 \pm 0.12^{\mathrm{a}}$ & $1.35 \pm 0.11^{\mathrm{b}}$ & $0.98 \pm 0.10^{\mathrm{b}}$ & $1.68 \pm 0.13^{\mathrm{c}}$ \\
\hline IDF, \% & $2.27 \pm 0.11^{\mathrm{a}}$ & $2.34 \pm 0.10^{\mathrm{a}}$ & $5.16 \pm 0.13^{b}$ & $3.15 \pm 0.11^{\mathrm{c}}$ & $6.89 \pm 0.13^{\mathrm{d}}$ \\
\hline Total polyphenols, mg/g DW & $50.0 \pm 0.3^{\mathrm{a}}$ & $83.0 \pm 3.4^{\mathrm{c}}$ & $164.5 \pm 2.8^{b}$ & $52.9 \pm 5.6^{\mathrm{a}}$ & $185.9 \pm 0.6^{\mathrm{d}}$ \\
\hline ORAC, $\mu \mathrm{mol} \mathrm{TE} / \mathrm{g}$ DW & $6.4 \pm 0.4^{\mathrm{a}}$ & $20.2 \pm 1.1^{\mathrm{c}}$ & $35.7 \pm 3.1^{\mathrm{b}}$ & $10.5 \pm 0.7^{\mathrm{d}}$ & $35.5 \pm 1.4^{\mathrm{b}}$ \\
\hline HORAC, $\mu \mathrm{mol} \mathrm{GAE} / \mathrm{g}$ DW & $2.3 \pm 0.3^{\mathrm{a}}$ & $5.7 \pm 1.3^{\mathrm{c}}$ & $16.0 \pm 2.1^{\mathrm{b}}$ & $2.2 \pm 0.6^{\mathrm{a}}$ & $12.0 \pm 1.0^{\mathrm{d}}$ \\
\hline
\end{tabular}

H/D ratio: the ratio of Height to Diameter of the muffins

TDF: Total Dietary Fibers; ${ }^{*}$ determined as sum of SDF and IDF

SDF: Soluble Dietary Fibers

IDF: Insoluble Dietary Fibers

ORAC: Oxygen Radical Absorbance Capacity assay

HORAC: Hydroxyl Radical Averting Capacity assay

TE: Trolox Equivalents

GAE: Gallic Acid Equivalents

The results were expressed as mean $\pm \mathrm{SD}(n=3)$

a, b, c, d Values with different letters in superscript (a, b, c, d) in a column are statistically significant (ANOVA, Tuckey's post hoc test, $p<0.05)$. With the letter a are denoted the highest determined value, and with the letter $\mathrm{d}$ - the lowest value; the others denotes values in between a and d. The values denoted with different letters (a, b, c, d) are different with level of significance $p<0.05$, meaning that $95 \%$ of the determined results differ.

times (comparing variant V1 with $\mathrm{C} 1$ ) and almost three times comparing variant $\mathrm{V} 3$ with $\mathrm{C} 2$. Therefore the variants V1 and V3, having $6.51 \pm 0.15 \%$ and $8.57 \pm 0.12 \%$ TDF respectively, could be considered as source of fibers bearing in mind that according to the European legislation such claim is permitted if the products have more than $3 \mathrm{~g}$ per $100 \mathrm{~g}$ food system [10]. The polyphenol content and antioxidant activity of control $(\mathrm{C} 1)$ had the lowest values.

The addition of low fat natural cocoa increased the total polyphenol content of muffins with $66 \%$ (C2) rendering significantly higher ORAC and HORAC antioxidant activities. However, the addition of $0.9 \mathrm{~g} \mathrm{CPH}$ flour (V2) did not result in increased polyphenol content but the addition of $1.6 \mathrm{~g}$ of RDCO2 flour augmented the polyphenol content and antioxidant activity more than 3- and 5-fold, respectively. This outlined that RDCO2 could be used as functional ingredients to improve overall antioxidant capacity of muffins. Addition of CPH to V1 slightly increased its polyphenol content and antioxidant activity (V3).

Furthermore image analysis of the muffins, giving information about the crumb porosity and the influence of the additives on the batter and final product properties, was performed. The pores dimensions, distribution pattern and fineness (Fig. S1) were expressed with five set in advance dimensional ranges based on the percentage of the total area of pores for each class compared to the total area of pores in the muffins. The data presented in Fig. S1 revealed that the gas pore area distribution of all samples follows normal left skewed to centered unimodal distribution. The results clearly demonstrated the predominating size classes in the different samples. In all samples more than $50 \%$ of the gas pores had an area $<1 \mathrm{~mm}^{2}$ with dominating samples V3 and V1 having respectively $75.6 \%$ and $74.9 \%$ of the gas pores within area class $<1 \mathrm{~mm}^{2}$. In the present study, similarly to [5], the percentage of gas cells having an area $<1 \mathrm{~mm}^{2}$ was considered as a quantitative factor that can be used to define gas pore fineness. The results presented in Table S4 correlated well with those for the specific volume of the analyzed muffins. The highest mean gas pore area $1.47 \mathrm{~mm}^{2}$ was observed for V2 sample with a corresponding specific volume of $1.95 \mathrm{~cm}^{3} / \mathrm{g}$.

\subsection{Shelf life of muffins}

The microbiological parameters of the muffins one hour after their preparation were determined. The results suggested that all samples tested met the standard microbiological safety requirements before their storage for 25 days: Coliforms (cfu/g) - under 100; Escherichia coli (cfu/g) - under 10; Salmonella sp. (cfu/g) - absence; coagulase-positive Staphylococci (cfu/g) - under 10; Bacillus cereus $(\mathrm{cfu} / \mathrm{g})$ - under 10; spores of microscopic fungi $(\mathrm{cfu} / \mathrm{g})$ - under 10. 
The stability and shelf life of bakery products is related to several major factors: microbial proliferation, water activity, temperature, presence of substances or microorganisms which could suppress microbial and fungal development and changes in the sensorial characteristics during storage. For this reason the muffins were stored for 25 days at controlled temperature and humidity and the changes of their water activity and spoilage was followed (Table 3). The amount of water (closely related to the water activity of the samples) was higher at the beginning in the three variants with added $\mathrm{CPH}$ and RDCO2 than the control samples. This could be related to the higher amounts of fibers in the muffins with replaced wheat flour (Table 2).

The water activity (above 0.9) was higher for the samples with added RDCO2 by-product although no statistically significant difference was observed. Similarly Lamdande et al. [6] found higher values for water activity of muffins prepared with jaggery. On contrary Singh et al. [9] reported lower water activity in muffins prepared with added carrot pomace dietary fiber

Table 3 Microbiological stability, water content and water activity of muffins stored at room temperature $\left(22 \pm 0.5^{\circ} \mathrm{C}\right)$

\begin{tabular}{|c|c|c|c|c|c|c|}
\hline Day & Parameter & $\mathrm{C} 1$ & $\mathrm{C} 2$ & V1 & $\mathrm{V} 2$ & V3 \\
\hline \multirow{4}{*}{0} & A & - & - & - & - & - \\
\hline & Aroma & No & No & No & No & No \\
\hline & Water, \% & $22.56 \pm 0.21^{\mathrm{a}}$ & $22.90 \pm 0.11^{\mathrm{a}}$ & $24.36 \pm 0.18^{b}$ & $22.71 \pm 0.14^{\mathrm{a}}$ & $23.99 \pm 0.20^{\mathrm{b}}$ \\
\hline & $a_{w}$ & $0.90 \pm 0.02$ & $0.91 \pm 0.01$ & $0.92 \pm 0.03$ & $0.93 \pm 0.03$ & $0.93 \pm 0.05$ \\
\hline \multirow{4}{*}{1} & A & - & - & - & - & - \\
\hline & Aroma & No & No & No & No & No \\
\hline & Water, $\%$ & $22.55 \pm 0.19^{\mathrm{a}}$ & $22.88 \pm 0.10^{\mathrm{a}}$ & $24.32 \pm 0.18^{\mathrm{b}}$ & $22.69 \pm 0.15^{\mathrm{a}}$ & $23.99 \pm 0.21^{\mathrm{b}}$ \\
\hline & $a_{w}$ & $0.90 \pm 0.01$ & $0.90 \pm 0.02$ & $0.92 \pm 0.01$ & $0.92 \pm 0.04$ & $0.93 \pm 0.01$ \\
\hline \multirow{4}{*}{5} & A & - & - & - & - & - \\
\hline & Aroma & No & No & No & No & No \\
\hline & Water, $\%$ & $22.54 \pm 0.15^{\mathrm{a}}$ & $22.87 \pm 0.17^{\mathrm{a}}$ & $24.33 \pm 0.09^{b}$ & $22.66 \pm 0.18^{\mathrm{a}}$ & $23.98 \pm 0.21^{\mathrm{b}}$ \\
\hline & $a_{w}$ & $0.89 \pm 0.01$ & $0.90 \pm 0.04$ & $0.90 \pm 0.04$ & $0.93 \pm 0.01$ & $0.93 \pm 0.01$ \\
\hline \multirow{4}{*}{10} & A & - & - & - & - & - \\
\hline & Aroma & No & No & No & No & No \\
\hline & Water, $\%$ & $22.52 \pm 0.18^{\mathrm{a}}$ & $22.85 \pm 0.20^{\mathrm{a}}$ & $24.32 \pm 0.14^{b}$ & $22.65 \pm 0.18^{\mathrm{a}}$ & $23.97 \pm 0.16^{\mathrm{c}}$ \\
\hline & $a_{w}$ & $0.89 \pm 0.02$ & $0.91 \pm 0.03$ & $0.90 \pm 0.01$ & $0.93 \pm 0.01$ & $0.92 \pm 0.03$ \\
\hline \multirow{4}{*}{15} & A & - & - & - & - & - \\
\hline & Aroma & No & No & No & No & No \\
\hline & Water, $\%$ & $22.30 \pm 0.16^{\mathrm{a}}$ & $22.44 \pm 0.18^{\mathrm{a}}$ & $23.96 \pm 0.20^{\mathrm{b}}$ & $22.37 \pm 0.10^{\mathrm{a}}$ & $23.71 \pm 0.11^{\mathrm{b}}$ \\
\hline & $a_{w}$ & $0.87 \pm 0.02$ & $0.90 \pm 0.01$ & $0.89 \pm 0.02$ & $0.91 \pm 0.02$ & $0.92 \pm 0.01$ \\
\hline \multirow{4}{*}{20} & A & SB & SB & - & - & - \\
\hline & Aroma & Yes & Yes & No & No & No \\
\hline & Water, $\%$ & $21.87 \pm 0.14^{\mathrm{a}}$ & $21.86 \pm 0.20^{\mathrm{a}}$ & $23.42 \pm 0.18^{\mathrm{b}}$ & $22.03 \pm 0.17^{\mathrm{a}}$ & $23.46 \pm 0.17^{\mathrm{b}}$ \\
\hline & $a_{w}$ & $0.84 \pm 0.04$ & $0.87 \pm 0.01$ & $0.87 \pm 0.03$ & $0.89 \pm 0.01$ & $0.90 \pm 0.01$ \\
\hline \multirow{4}{*}{22} & A & $\mathrm{S}$ & $\mathrm{S}$ & SB & SB & - \\
\hline & Aroma & Yes & Yes & Yes & Yes & No \\
\hline & Water, $\%$ & $21.78 \pm 0.15^{\mathrm{a}}$ & $21.62 \pm 0.13^{\mathrm{a}}$ & $23.32 \pm 0.11^{\mathrm{b}}$ & $21.75 \pm 0.11^{\mathrm{a}}$ & $23.29 \pm 0.15^{\mathrm{b}}$ \\
\hline & $a_{w}$ & $0.83 \pm 0.01$ & $0.85 \pm 0.02$ & $0.86 \pm 0.01$ & $0.88 \pm 0.01$ & $0.90 \pm 0.01$ \\
\hline \multirow{4}{*}{23} & A & $\mathrm{S}$ & $\mathrm{S}$ & $\mathrm{S}$ & $\mathrm{S}$ & $\mathrm{S}$ \\
\hline & Aroma & Yes & Yes & Yes & Yes & Yes \\
\hline & Water, \% & $21.50 \pm 0.10^{\mathrm{a}}$ & $21.45 \pm 0.11^{\mathrm{a}}$ & $23.06 \pm 0.09^{b}$ & $21.46 \pm 0.08^{\mathrm{a}}$ & $23.02 \pm 0.12^{\mathrm{b}}$ \\
\hline & $a_{w}$ & nd & nd & $0.84 \pm 0.02$ & $0.86 \pm 0.03$ & $0.87 \pm 0.02$ \\
\hline
\end{tabular}

The results were presented as mean $\pm \mathrm{SD}(n=4)$;

$a_{w}$ - water activity;

A - SB: Spoilage Beginning is considered when single colony was observed; S: Spoilage

Aroma - "Yes" when the first distinctive notes of sharp odor are sensed;

nd - not measured due to significant spoilage

a, b - Values with different letters in superscript $(\mathrm{a}, \mathrm{b})$ in a column are statistically significant (ANOVA, Tuckey's post hoc test, $p<0.05$ ). With the letter a are denoted the highest determined value, and with the letter $b$ - the lowest value. The values denoted with different letters (a, $b)$ are different with level of significance $p<0.05$, meaning that $95 \%$ of the determined results differ. 
concentrate and xanthan gum which suggested that the supplements strongly affect the ability of the final product to bind firmly the water molecules.

Of particular importance for such foods is fungal and bacterial spoilage. Therefore, fungal and bacterial spoilage of the baked muffins was monitored by storage at $22 \pm 0.5^{\circ} \mathrm{C}$. No bacterial spoilage of the muffins was observed during 15 days of storage. The reduction of the water activity $\left(a_{w}\right)$ of the muffins led to reduction of the crumb softness which influenced the firmness but all the variants were still enough palatable after 16 days of storage. In control samples ( $\mathrm{C} 1$ and $\mathrm{C} 2)$ these changes were established at the $17-18^{\text {th }}$ day of storage and were accompanied also by appearance of unpleasant smell. For samples V1 with $\mathrm{CPH}$ and V2 with $\mathrm{RDCO} 2$ the reduction in the crumb softness and the appearance of unpleasant smell without fungal spoilage appeared 2 days later on the $20^{\text {th }}$ day of storage. The V3, with added $\mathrm{CPH}$ and RDCO2, withstands for two more days. Similar results were observed by Lamdande et al. [6] investigating the microbiological stability and sensory characteristics of muffins with jaggery as sucrose replacer (Table 3).

\subsection{Sensory characteristics of muffins}

The shelf life extension and functionalization of bakery products could be made by addition of different raw materials, substances and extracts but the most important acceptance criterion remains the consumers' opinion. For this reason in the next experiments the muffins were provided to 19 panelists in order to evaluate the overall appearance and acceptance of the products (Fig. 2).

All the samples, except the $\mathrm{C} 1$ (only with wheat flour), were distinguished with intensive crust color and the same is valid also for the crumb color. This was expected due

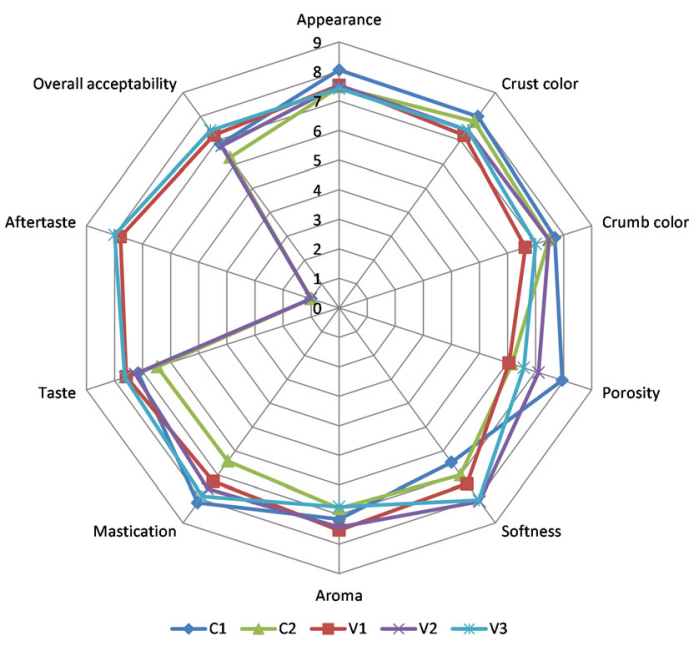

Fig. 2 Sensory characteristics of muffins to the dark color of the added $\mathrm{CPH}$ and RDCO2. No differences in the mastication of the samples were reported, except for the $\mathrm{C} 2$ which was surprisingly the least accepted one. The substantial differences existed for the porosity of the crumb. The $\mathrm{C} 1$ has the highest porosity (which is also confirmed by the image analysis results, Fig. S1) compared to the other variants. Similar results were reported by Vasileva et al. [5] for breads with added melissa and lavender by-products. The aroma and the taste of the muffins were well accepted by the panelists. The most significant differences were observed for the aftertaste. For variants V1 and V3 (with added RDCO2) the panelists reported strong aroma of roses. The opinions of the tasters differed: some considered the rose aroma as acceptable and pleasant, and others - as inappropriate and unusual. In general the overall acceptability of the muffins did not differ substantially and the panelists found that the addition of $\mathrm{CPH}$ and RDCO2 led to formulation of products with pleasant taste and distinctive fragrance.

\section{Conclusion}

The present study explored utilization of Cocoa Pod Husks and Rosa damascena Mill. by-product (obtained after supercritical $\mathrm{CO}_{2}$ extraction), as biopreservatives and functionalizing additives in muffins. For the first time, to the best of our knowledge, solid by-product remained after $\mathrm{CO}_{2}$ extraction of Rosa damascena Mill., was characterized and used as biopreservative and functionalizing additive in bakery products. Three variants: with added RDCO2 flour (V1), with replacement of the commercial cocoa with CPH flour (V2) and with addition of both $\mathrm{CPH}$ and RDCO2 flour (V3), and two controls: without $(\mathrm{C} 1)$ and with $(\mathrm{C} 2)$ commercial cocoa powder were prepared. The results of analyses for preliminary characterization of $\mathrm{CPH}$ and $\mathrm{RDCO} 2$ suggested that the by-products were rich source of antioxidants. Extracts of both by-products showed potent inhibitory effect against common pathogens which gave ground to be incorporated in food systems as biopreservatives. The rheological studies of the batters indicated pseudoplastic behavior and non-Newtonian nature of all the variants. The batter of V3 combination, in which both RDCO2 and $\mathrm{CPH}$ were used to replace wheat flour, had the highest value of yield stress: $7.18 \mathrm{~Pa}$. Addition of RDCO2 led to increase of Total Dietary Fiber (up to three times, comparing V3 and $\mathrm{C} 1$ ) and polyphenol content in muffins. All the variants prepared had more than $50 \%$ of the gas pores area below $1 \mathrm{~mm}^{2}$ with $\mathrm{V} 3$ and $\mathrm{V} 1$ having $75.6 \%$ and $74.9 \%$, respectively, of pores less than $1 \mathrm{~mm}^{2}$. Similar effect was 
observed by Vasileva et al. [5] and the percentage of gas cells having area $<1 \mathrm{~mm}^{2}$ was considered as a quantitative factor of gas pore fineness. The controls were good for consumption up to the $17-18^{\text {th }}$ day, while samples V1 with CPH and V2 with RDCO2: until $20^{\text {th }}$ day of storage at $22 \pm 0.5^{\circ} \mathrm{C}$. The V3, with added $\mathrm{CPH}$ and RDCO2, withstands for two more days which confirmed the beneficial effect of RDCO2 and $\mathrm{CPH}$ addition on the muffins shelf life extension. The sensory analysis revealed that in general the overall acceptability of the muffins did not differ substantially and the panelists found that the addition

\section{References}

[1] Lee, E. J., Moon, Y., Kweon, M. "Processing suitability of healthful carbohydrates for potential sucrose replacement to produce muffins with staling retardation", LWT, 131, Article number: 109565, 2020. https://doi.org/10.1016/j.lwt.2020.109565

[2] Rizzello, C. G., Verni, M., Bordignon, S., Gramaglia, V., Gobbetti, M. "Hydrolysate from a mixture of legume flours with antifungal activity as an ingredient for prolonging the shelf-life of wheat bread", Food Microbiology, 64, pp. 72-82, 2017.

https://doi.org/10.1016/j.fm.2016.12.003

[3] Denkova, R., Ilieva, S., Denkova, Z., Georgieva, L., Yordanova, M., Nikolova, D., Evstatieva, Y. "Production of wheat bread without preservatives using sourdough starters", Biotechnology and Biotechnological Equipment, 28(5), pp. 889-898, 2014. https://doi.org/10.1080/13102818.2014.965057

[4] Giatrakou, V., Ntzimani, A., Savvaidis, I. N. "Effect of chitosan and thyme oil on a ready to cook chicken product", Food Microbiology, 27(1), pp. 132-136, 2010.

https://doi.org/10.1016/j.fm.2009.09.005

[5] Vasileva, I., Denkova, R., Chochkov, R., Teneva, D., Denkova, Z., Dessev, T., Denev, P., Slavov, A. "Effect of lavender (Lavandula angustifolia) and melissa (Melissa Officinalis) waste on quality and shelf life of bread", Food Chemistry, 253, pp. 13-21, 2018. https://doi.org/10.1016/j.foodchem.2018.01.131

[6] Lamdande, A. G., Khabeer, S. T., Kulathooran, R., Dasappa, I. "Effect of replacement of sugar with jaggery on pasting properties of wheat flour, physico-sensory and storage characteristics of muffins", Journal of Food Science and Technology, 55(8), pp. 3144-3153, 2018.

https://doi.org/10.1007/s13197-018-3242-7

[7] Martínez-Cervera, S., Sanz, T., Salvador, A., Fizsman, S. M. "Rheological, textural and sensorial properties of low-sucrose muffins reformulated with sucralose/polydextrose", LWT - Food Science and Technology, 45(2), pp. 213-220, 2012. https://doi.org/10.1016/j.lwt.2011.08.001

[8] Martínez-Cervera, S., Salvador, A., Muguerza, B., Moulay, L., Fiszman, S. M. "Cocoa fibre and its application as a fat replacer in chocolate muffins", LWT - Food Science and Technology, 44(3), pp. 729-736, 2011.

https://doi.org/10.1016/j.lwt.2010.06.035 of $\mathrm{CPH}$ and $\mathrm{RDCO} 2$ led to preparation of products with pleasant taste and distinctive fragrance. The results from the present study suggested that $\mathrm{CPH}$ and $\mathrm{RDCO} 2$ could be successfully utilized as additives for preparation of muffins: for shelf life prolongation and functionalization of bakery products.

\section{Acknowledgement}

This work was supported by the Science Fund of University of Food Technologies (grant 02/19-H) and the National Science Fund of Bulgaria (grant DN 17/22).

[9] Singh, J. P., Kaur, A., Singh, N. "Development of eggless gluten-free rice muffins utilizing black carrot dietary fibre concentrate and xanthan gum", Journal of Food Science and Technology, 53(2), pp. 1269-1278, 2016. https://doi.org/10.1007/s13197-015-2103-x

[10] Nath, P., Kale, S. J., Kaur, C., Chauhan, O. P. "Phytonutrient composition, antioxidant activity and acceptability of muffins incorporated with red capsicum pomace powder", Journal of Food Science and Technology, 55(6), pp. 2208-2219, 2018. https://doi.org/10.1007/s13197-018-3138-6

[11] Rupasinghe, H. P. V., Wang, L., Huber, G. M., Pitts, N. L. "Effect of baking on dietary fibre and phenolics of muffins incorporated with apple skin powder", Food Chemistry, 107(3), pp. 1217-1224, 2008. https://doi.org/10.1016/j.foodchem.2007.09.057

[12] Slavov, A., Denev, P., Panchev, I., Shikov, V., Nenov, N., Yantcheva, N., Vasileva, I. "Combined recovery of polysaccharides and polyphenols from Rosa damascena wastes", Industrial Crops and Products, 100, pp. 85-94, 2017.

https://doi.org/10.1016/j.indcrop.2017.02.017

[13] Oddoye, E. O. K., Agyente-Badu, C. K., Gyedu-Akoto, E. "Cocoa and Its By-Products: Identification and Utilization", In: Watson, R. R., Preedy, V. R., Zibadi, S. (eds.) Chocolate in Health and Nutrition, Humana Press, New York, USA, 2013, pp. 23-37. https://doi.org/10.1007/978-1-61779-803-0_3

[14] Vasileva, I., Krastev, L., Slavov, A. M., Petkova, N., Yantcheva, N., Nenov, N., Krachmarov, A., Atanasova, A. "Valorization of cocoa and rose waste for preparation of liqueurs", Food Science and Applied Biotechnology, 2(1), pp. 8-17, 2019. https://doi.org/10.30721/fsab2019.v2.i1.41

[15] Galanakis, C. M. "Separation of functional macromolecules and micromolecules: From ultrafiltration to the border of nanofiltration", Trends in Food Science and Technology, 42(1), pp. 44-63, 2015. https://doi.org/10.1016/j.tifs.2014.11.005

[16] Roselló-Soto, E., Barba, F. J., Parniakov, O., Galanakis, C. M., Lebovka, N., Grimi, N., Vorobiev, E. "High Voltage Eletctrical Discharges, Pulsed Electric Field and Ultrasound Assisted Extraction of Protein and Phenolic Compounds from Olive Kernel", Food and Bioprocess Technology, 8, pp. 885-894, 2015. https://doi.org/10.1007/s11947-014-1456-x 
[17] Barba, F. J., Galanakis, C. M., Esteve, M. J., Frigola, A., Vorobiev, E. "Potential use of pusled electric technologies and ultrasounds to improve the recovery of high-added value compounds from blackberries", Journal of Food Engineering, 167, pp. 38-44, 2015. https://doi.org/10.1016/j.jfoodeng.2015.02.001

[18] Kovačević, D. B., Barba, F. J., Granato, D., Galanakis, C. M., Herceg, Z., Dragović-Uzelac, V., Putnik, P. "Pressurized hot water extraction (PHWE) for the green recovery of bioactive compounds and steviol glycosides from Stevia rebaudiana Bertoni leaves", Food Chemistry, 254, pp. 150-157, 2018. https://doi.org/10.1016/j.foodchem.2018.01.192

[19] Galanakis, C. M. "The Food Systems in the Era of the Coronavirus (COVID-19) Pandemic Crisis", Foods, 9(4), Article number: 523, 2020.

https://oi.org/10.3390/foods9040523

[20] Galanakis, C. M., Aldawoud, T. M. S., Rizou, M., Rowan, N. J., Ibrahim, S. A. "Food Ingredients and Active Compounds against the Coronavirus Disease (COVID-19) Pandemic: A Comprehensive Review", Foods, 9(11), Article number: 1701, 2020. https://doi.org/10.3390/foods9111701

[21] Karneva, K. B., Vasileva, I. N., Denev, P. N., Denkova, R. S., Shikov, V. T., Manolova, M. N., Lazarova, Y. L., Ivanova, V. N., Slavov, A. M. "Valorization of Lavender Waste-Obtaining and Characteristics of Polyphenol Rich Extracts", Food Science and Applied Biotechnology, 1(1), pp. 11-18, 2018. https://doi.org/10.30721/fsab2018.v1.i1.5

[22] Singleton, V. L., Rossi, J. A. "Colorimetry of Total Phenolics with Phosphomolybdic-Phosphotungstic Acid Reagents", American Journal of Enology and Viticulture, 16, pp. 144-158, 1965. [online] Available at: https://www.ajevonline.org/content/16/3/144 [Accessed: 06 January 2021]

[23] Rahmanian, N., Jafari, S. M., Galanakis, C. M. "Recovery and Removal of Phenolic Compounds from Olive Mill Wastewater", Journal of the American Oil Chemists' Society, 91(1), pp. 1-18, 2014. https://doi.org/10.1007/s11746-013-2350-9

[24] Galanakis, C. M. "Phenols recovered from olive mill wastewater as additives in meat products", Trends in Food Science and Technology, 79, pp. 98-105, 2018. https://doi.org/10.1016/j.tifs.2018.07.010

[25] Galanakis, C. M., Tsatalas, P., Galanakis, I. M. "Implementation of phenols recovered from olive mill wastewater as UV booster in cosmetics", Industrial Crops and Products, 111, pp. 30-37, 2018. https://doi.org/10.1016/j.indcrop.2017.09.058

[26] Nagarajan, J., Krishnamurthy, N. P., Ramanan, R. N., Raghunandan, M. E., Galanakis, C. M., Ooi, C. W. "A facile water-induced complexation of lycopene and pectin from pink guava byproduct: Extraction, characterization and kinetic studies", Food Chemistry, 296, pp. 47-55, 2019. https://doi.org/10.1016/j.foodchem.2019.05.135

[27] Zinoviadou, K. G., Galanakis, C. M., Brnčić, M., Grimi, N., Boussetta, N., Mota, M. J., Saraiva, J. A., Patras, A., Tiwari, B., Barba, F. J. "Fruit juice sonication: Implications on food safety and physicochemical and nutritional properties", Food Research International, 77(4), pp. 743-752, 2015. https://doi.org/10.1016/j.foodres.2015.05.032
[28] Slavov, A. M., Denev, P. N., Denkova, Z. R., Kostov, G. A., Denkova-Kostova, R. S., Chochkov, R. M., Deseva, I. N., Teneva, D. G. "3 - Emerging cold pasteurization technologies to improve shelf life and ensure food quality", In: Galanakis, C. M. (ed.) Food Quality and Shelf Life, Academic Press-Elsevier Inc., London, UK, 2019, pp. 55-123. https://doi.org/10.1016/B978-0-12-817190-5.00003-3

[29] Galanakis, C. M., Rizou, M., Aldawoud, T. M. S., Ucak, I., Rowan, N. J. "Innovations and technology disruptions in the food sector within the COVID-19 pandemic and post-lockdown era", Trends in Food Science and Technology, 110, pp. 193-200, 2021. https://doi.org/10.1016/j.tifs.2021.02.002

[30] Raybaudi-Massilia, R. M., Mosqueda-Melgar, J., MartínBelloso, O. "Antimicrobial activity of malic acid against Listeria monocytogenes, Salmonella Enteritidis and Escherichia coli O157:H7 in apple, pear and melon juices", Food Control, 20(2), pp. 105-112, 2009. https://doi.org/10.1016/j.foodcont.2008.02.009

[31] Borges, A., Ferreira, C., Saavedra, M. J., Simões, M. "Antibacterial Activity and Mode of Action of Ferulic and Gallic Acids Against Pathogenic Bacteria", Microbial Drug Resistance, 19(4), pp. 256-265, 2013. https://doi.org/10.1089/mdr.2012.0244

[32] Kartal, M., Yıldız, S., Kaya, S., Kurucu, S., Topçu, G. "Antimicrobial activity of propolis samples from two different regions of Anatolia", Journal of Ethnopharmacology, 86(1), pp. 69-73, 2003. https://doi.org/10.1016/S0378-8741(03)00042-4

[33] Corre, J., Lucchini, J. J., Mercier, G. M., Cremieux, A. "Antibacterial activity of phenethyl alcohol and resulting membrane alterations", Research in Microbiology, 141(4), pp. 483-497, 1990. https://doi.org/10.1016/0923-2508(90)90074-Z

[34] Cho, J.-Y., Moon, J.-H., Seong, K.-Y., Park, K.-H. "Antimicrobial Activity of 4-Hydroxybenzoic Acid and trans 4-Hydroxycinnamic Acid Isolated and Identified from Rice Hull", Bioscience, Biotechnology and Biochemistry, 62(11), pp. 2273-2276, 1998. https://doi.org/10.1271/bbb.62.2273

[35] Delaquis, P., Stanich, K., Toivonen, P. "Effect of $\mathrm{pH}$ on the Inhibition of Listeria spp. by Vanillin and Vanillic Acid", Journal of Food Protection, 68(7), pp. 1472-1476, 2005. https://doi.org/10.4315/0362-028x-68.7.1472

[36] Alves, M. J., Ferreira, I. C. F. R., Froufe, H. J. C., Abreu, R. M. V., Martins, A., Pintado, M. "Antimicrobial activity of phenolic compounds identified in wild mushrooms, SAR analysis and docking studies", Journal of Applied Microbiology, 115(2), pp. 346-357, 2013. https://doi.org/10.1111/jam.12196

[37] Baixauli, R., Sanz, T., Salvador, A., Fiszman, S. M. "Muffins with resistant starch: Baking performance in relation to the rheological properties of the batter", Journal of Cereal Science, 47(3), pp. 502-509, 2008. https://doi.org/10.1016/j.jcs.2007.06.015

[38] Panchev, I. N., Toshkov, N. G., Nenov, V. B., Simitchiev, A. T. "Opportunities for Waste Materials Utilization by Extrusion in Processing Cocoa Seeds", Journal of Food and Packaging Science, Technique and Technologies, 3(2), pp. 299-302, 2013. 